Session 2793

\title{
Active learning and action research - basic attributes of a support course for first year engineering students
}

\author{
Tobia Steyn, Jasper Steyn \\ School of Engineering, University of Pretoria, South Africa
}

\begin{abstract}
This paper reports on active learning and action research during 2000-2001, involving first-year engineering students on a support course in the School of Engineering at the University of Pretoria, South Africa. Students on the support course have passed the university's admission tests assessing their ability to succeed at engineering studies. However, they are academically still at risk because of deficiencies in their educational background. The support course is designed to redress and enhance students' concept of the fundament als underpinning a study in calculus, to aid the development of personal, academic and communication skills and to give the students basic skills in information technology. The main pedagogical approach is aimed at developing the full academic potential of the students. The study focused on determining students' learning preferences, their study orientation in mathematics and the development of writing skills relevant for engineering. The Herrmann Brain Dominance Instrument was used to determine the students' thinking style preferences. This information was used to foster an awareness of the existence of diversity in thinking and learning preferences as well as the need to develop an ability to access less preferred modes of thinking and learning. Analysis of data obtained from the Study Orientation Questionnaire in Mathematics shows that these students enter tertiary education with a high level of mathematics anxiety and a lack of skills that contribute to understanding mathematics. They are therefore provid ed with additional support in mathematics concepts using computer graphing technology to visualise and explore the graphs of two-dimensional functions in an active learning environment. The principal pedagogy regarding the development of the students' writing skills for engineering include active "learning by doing" and co-operative learning in a "buddy assessment" system. Initial indications are that active learning and action research are complementary and beneficial to both students and faculty and can contribute to continual improvement of practice.
\end{abstract}

\section{Background: Five Year Program}

The standard university engineering program in South Africa requires four years of full time study as regulated by the Engineering Council of South Africa (ECSA). In 1994 the Five Year Study Program was introduced in the School of Engineering at the University of Pretoria. This program increases the duration of the standard engineering study from four years to five years. This is

Proceedings of the 2002 American Society for Engineering Education Annual Conference \& Exposition Copyright $\odot$ 2002, American Society for Engineering Education 
arranged in such a way that the academic courses of the first two years of the Four Year Program are spread over the first three years of the Five Year Program. The purpose of the Five Year Program is to create an opportunity for students who have the potential to become engineers but who do not meet the entrance requirements for the Four Year Program and/or are academically at risk because of their educational background. Students on the Five Year Program are given extensive academic support in their first year engineering courses through tutoring given by senior (engineering) students.

\section{Background: The Professional Orientation support course}

In spite of the support through tutoring, some of the students on the Five Year Program are academically still at risk of not succeeding at engineering study. Factors that contribute to the difficulties that these students experience are the varying levels of educational competency in South African schools and a lack of exposure and access to technology. For these students an additional two-semester credit-bearing support course, Professional Orientation, is offered during the first year of study. The course comprises of a conceptual mathematics component, the development of personal skills, communication skills and skills in information technology. The course content provides a broad academic background to mainly black students who are presently an underrepresented minority in engineering study in South Africa.

\section{Background: Deficiencies in educational background}

Admission to study at the University of Pretoria is based on the calculation of a so called Mscore. An M-score is calculated from a student's final school examination results. For engineering study a minimum M-score of 18 points out of a possible 30 points is required. For prospective engineering students with an M-score ranging from 12 to 17 an additional admission test is given. Admission to the Five Year Program is then considered on the results of the test. The data ${ }^{[1,2]}$ in Table 1 indicates that the average M-score for the students on the support course is lower than that of the other Five Year Program students and is significantly lower than that of the students on the standard Four Year Program in both the 2000 and 2001 intake of first year engineering students. These figures provide an indication of the deficiencies in these students' schooling and of the resulting challenges associated with the facilitation of learning in the Professional Orientation support course.

Table 1 M-scores of first year engineering students at the University of Pretoria in 2000 and 2001

\begin{tabular}{|l|c|c|}
\cline { 2 - 3 } \multicolumn{1}{c|}{} & \multicolumn{2}{c|}{ Average M-score } \\
\hline Students & $\mathbf{2 0 0 0}$ & $\mathbf{2 0 0 1}$ \\
\hline Standard Four Year Program & 24.8 & 24.7 \\
\hline Professional Orientation Support course & 17.9 & 17.1 \\
\hline Other Five Year Program & 18.5 & 19.4 \\
\hline
\end{tabular}

Proceedings of the 2002 American Society for Engineering Education Annual Conference \& Exposition Copyright $\odot$ 2002, American Society for Engineering Education 


\section{Background: Language and computer literacy}

In the Professional Orientation class of 2000 there were 33 students of whom five were female and in 2001 there were 40 students of whom 13 were female. English is the second language of all the students. English is the predominant language of engineering practice in South Africa and is also the language of engineering tuition for these students. Deficient educational background in English constitutes a particular challenge for these students' teaching and learning.

In both the 2000 and 2001 classes about half of the students had had no prior experience in personal computer use and the others had had limited access to computers comprising two to three hours per week during their final high school years. Only three students in the 2001 group indicated that they had had prior experience using a personal computer. These figures provide an indication of the deficiencies in computer literacy of students on the Professional Orientation support course. As computer software is used extensively in engineering studies, this deficiency has to be addressed early in the study program.

\section{Course structure}

During the first semester of the two semesters of the support course, Professional Orientation, formal contact with the students consists of five fifty-minute classes per week. During the second semester there are four fifty minute classes and a three-hour practical session per week. The practical sessions are also used for visits to industry, construction sites, etc. This is done to enhance students' understanding of engineering practice.

The classes of the first semester focus on the mathematics component, the development of personal and study skills and an introduction to research and information technology. The strong focus on mathematics is due to the fact that the students need this remedial and developmental support for the core calculus course during this semester.

In the second semester the development of communication skills and specifically language writing skills needed for engineering study is the major focus. Writing competencies expected of engineering students are English composition and the ability to convey information appropriately to a specific audience. Writing in the Professional Orientation support course include scientific comprehension, report writing on practicals and experiments, research reports and reports on visits to industry. Basic training in the use of computer technology is incorporated in the writing process.

\section{Teaching and learning approach}

The main aim of the Professional Orientation support course is the development of each student's academic potential in order for him or her to pursue engineering studies successfully. Overall the educational activities in this course are viewed as "contributive learning" ${ }^{[3]}$ in the sense that faculty and students are participants in a dynamic process whereby teaching and learning are improved through the contribution of both faculty and students to each other's learning. This learning is not 
confined to subject content and can be diverse including aspects of student learning as well as successes and pitfalls of instructional activities.

\section{Whole brain teaching and learning}

Students arrive at tertiary institutions with established thinking style preferences and ensuing learning styles that influence all cognitive activities including conceptualisation of content. ${ }^{[4,5]}$ Teaching styles interact with learning styles to discourage or encourage students depending on the mismatch or match of a particular teaching style with students' learning styles. ${ }^{[4]}$ In order to accommodate individual students' diverse thinking style preferences and encourage the utilisation of their less preferred competencies, the teaching and learning strategy in the Professional Orientation support course can be termed as a four-quadrant whole brain approach. This approach is based on ongoing research since the 1970's on the functioning of the human brain that have indicated that specialised cognitive functions can be associated with different parts of the brain. For approximately $90 \%$ of the population ${ }^{[6]}$ logical, analytical, quantitative and fact based knowledge is located in the left brain hemisphere whereas the right brain hemisphere predominantly supports and co-ordinates intuition, emotion, spatial perception and kinaesthetic feelings. In the case of the other $10 \%$ of people the location of these functions is transposed.

Herrmann ${ }^{[5]}$ combined this knowledge with how the brain is physiologically organised to develop a four-quadrant whole brain model. Figure 1 illustrates an adaptation ${ }^{[7]}$ of Herrmann's model that also includes the following four modes ${ }^{[8]}$ describing student learning:

- External learning is related to learning through listening (lectures) and reading of textbooks, scientific literature, etc.

- Internal learning is related to learning through an insight, understanding of concepts holistically and intuitively, synthesis of data and personalising content into context.

- Interactive learning is from experience, hands-on activities, discussion and feedback.

- Procedural learning is characterised by a methodical approach, practise, repetition and testing.

If learning activities are structured to include different modes of student learning (implying different thinking and learning preferences), a whole brain approach is followed and competence in mastering concepts is fostered. Furthermore, functioning in any professional capacity requires working well in all thinking style modes. ${ }^{\text {[9] }}$ 
Figure 1 A four-quadrant whole brain approach to teaching and learning ${ }^{[7]}$

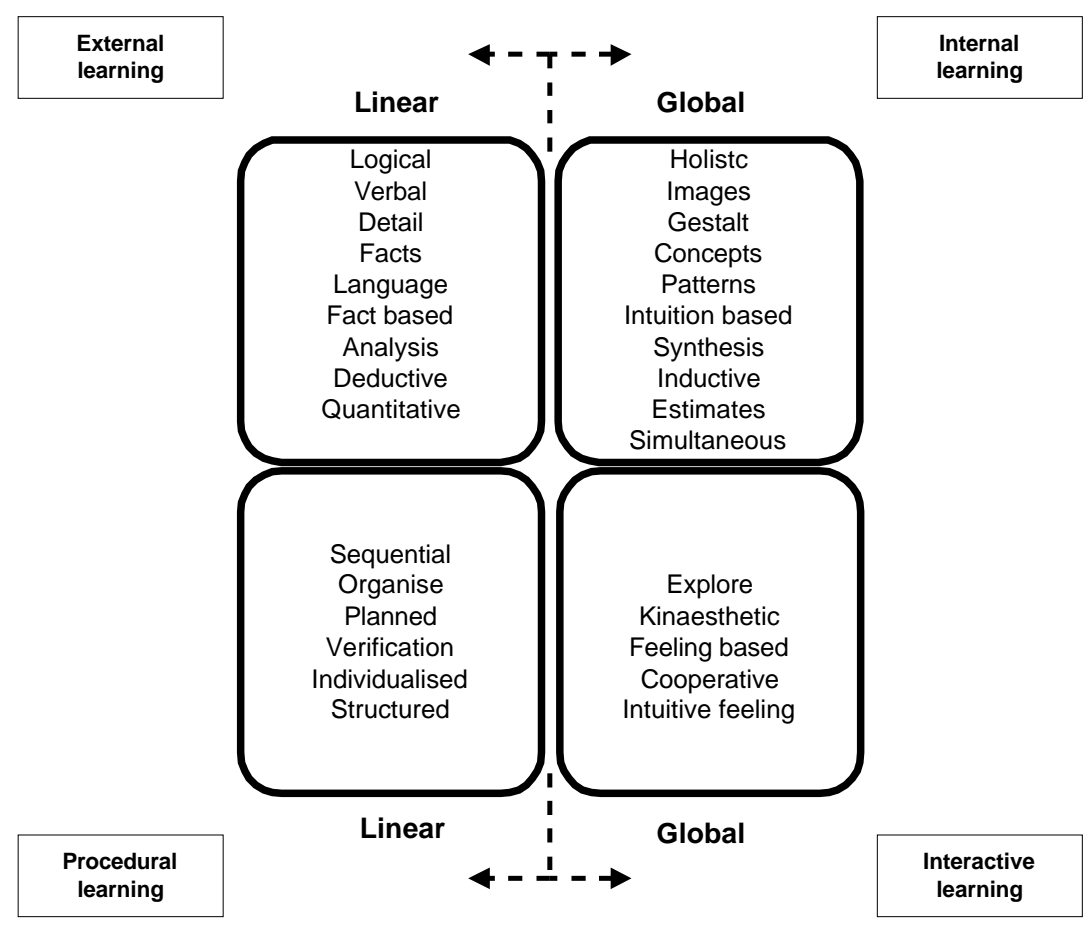

\section{Active learning}

Superimposed on the four-quadrant whole brain principle, active learning is viewed as a further core pedagogical principle in the support course. In this context active learning involves activities that engage students in doing something instead of only observing what can or should be done.

During 2000-2001 this developmental approach, based on the principles of whole brain learning facilitation and active learning, was structured as an action research study that included the determining of the students' thinking preferences, their study orientation in mathematics and the development of writing skills. In the following sections these aspects of the study are discussed.

\section{Thinking and learning preferences}

During 2000 the Herrmann Brain Dominance Instrument (HBDI $)^{[5]}$ was used to give students insight into their own thinking preferences and to measure the preferred thinking styles of the students. In addition the following hypotheses were investigated:

H1 Whether the arithmetic mean values of the scores for the quadrants of the HBDI differ between the students on the Professional Orientation support course and a group of first year civil engineering students on the Four Year Program. 
$\mathrm{H} 2$ Whether the arithmetic mean values of the scores for the quadrants of the HBDI differ between first year engineering students on a Professional Orientation support course and first year science students on a support course.

This part of the study involved 101 students. Of these students, 33 were on the engineering Professional Orientation support course, 30 were first year civil engineering students on the Four Year Program and 38 were first year science students on a support course. The data pertaining to HBDI of the latter group was determined during a research project in the Faculty of Science during 1999. ${ }^{[10]}$

The HBDI is an assessment tool comprising a survey of 120 questions that quantifies relative preference for thinking modes based on the hypothesized task-specialized functioning of the physical brain. A thinking preference profile, compiled from scores on an inventory, is displayed on a four-quadrant grid. The higher a score in a quadrant, the stronger the preference for the thinking style related to that quadrant. The Herrmann Brain Dominance profiles in Figure 2 are examples from the study and illustrate the tilt when a strong preference for the thinking mode associated with a specific quadrant is dominant.

A preference for the A-quadrant (upper left quadrant in Figure 2A) means that a person favors activities that involve critical, logical, analytical and fact-based information. Individuals with a Bquadrant preference (lower left quadrant in Figure 2B) favor organized, planned and detailed information. A preference for the C-quadrant (lower right quadrant in Figure 2C) indicates favoring information that is interpersonal, feeling based and involves emotion. A preference for the D-quadrant (upper right quadrant in Figure 2D) is mainly characterized by a visual, holistic and conceptual approach in thinking. Existing thinking preferences inevitably influence student s' learning preferences.

Figure 2 Individual profiles showing thinking preferences according to the HBDI

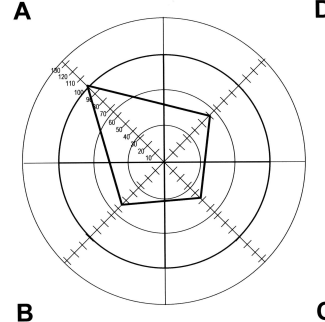

Figure 2A

Profile showing an A-quadrant thinking preference

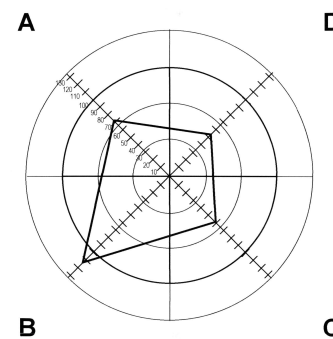

Figure 2B

Profile showing a B-quadrant thinking preference

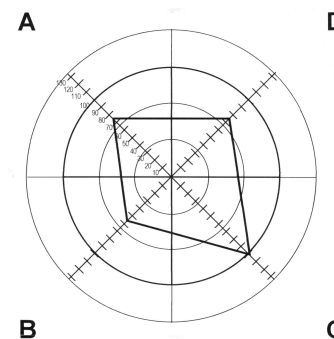

Figure 2C Profile showing a C-quadrant thinking preference
D A

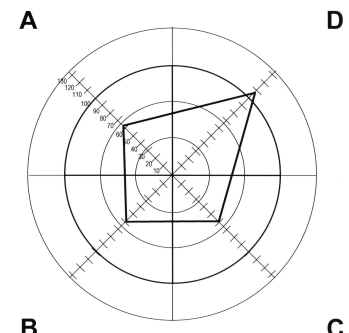

Figure 2D Profile showing a D-quadrant thinking preference 
In Table 2 the distribution of the number of students per quadrant of preference is given which shows that the majority of engineering students have thinking preferences associated with the Aquadrant.

Table 2 Number of Professional Orientation, civil engineering and science students with thinking preferences per quadrant

\begin{tabular}{|l|c|c|c|c|}
\cline { 2 - 5 } \multicolumn{1}{c|}{} & A & B & C & D \\
\hline Professional Orientation students & 17 & 5 & 5 & 6 \\
\hline Civil engineering students & 18 & 3 & 6 & 3 \\
\hline Science students & 9 & 18 & 7 & 4 \\
\hline
\end{tabular}

The diagrams in Figure 3 show the distribution of the individual profiles for each of the groups. Each point in the scatter plots represents the profile of strongest quadrant of preference of an individual. These diagrams indicate the distribution of profiles for a group of individuals. The diagrams in Figure 3A and in Figure 3B represent the distribution of preference profiles for two groups of engineering students. Both figures illustrate dominance in the distribution of profiles in the upper left A-quadrant. The diagram in Figure 3C represents the distribution of preference profiles for a group of science students and illustrates a dominance in the distribution of profiles in the lower left B-quadrant.

Figure 3 Distribution of thinking style preferences per group

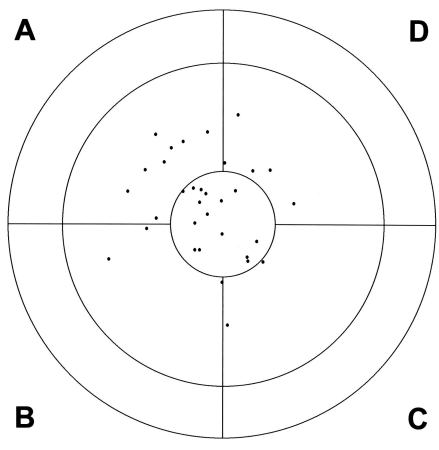

Figure $3 \mathrm{~A}$

Dominance map of the distribution of profiles for the Professional Orientation students in 2000

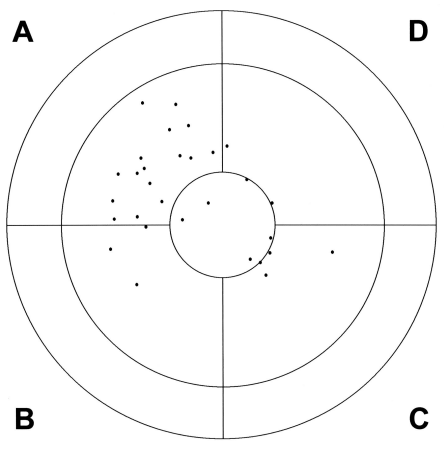

Figure 3B

Dominance map of the distribution of profiles for the civil engineering students in 2000

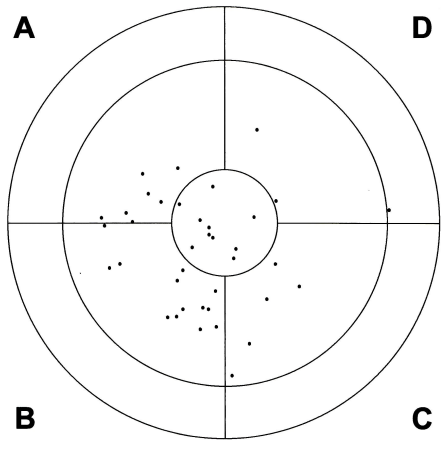

Figure 3C Dominance map of the distribution of profiles for the science students in 1999

The data presented in Table 2 and Figure 3 is in accordance with research that engineers (engineering students) typical favor A-quadrant thinking. ${ }^{[5,8,11]}$ However, the majority of science students on a support course have thinking preferences associated with the B-quadrant. 
The two-sample non-parametric Wilcoxon Rank Sum Test (normal approximation) was used to compare the arithmetic mean score values between the different groups for each of the four quadrants of the HBDI. Table 3 gives the arithmetic mean $(\bar{x})$, standard deviation $(s)$ and P-value regarding the quadrants of the HBDI for the Professional Orientation and civil engineering students and Table 4 gives the same data for the engineering students on a support course and science students on a support course.

Table 3 Wilcoxon scores for Professional Orientation and civil engineering students and the quadrants of the HBDI

\begin{tabular}{|c|c|c|c|c|l|}
\cline { 2 - 5 } \multicolumn{1}{c|}{} & $\begin{array}{c}\text { Professional Orientation } \\
\text { group (N=33) }\end{array}$ & \multicolumn{2}{c|}{$\begin{array}{c}\text { Civil engineering } \\
\text { group (N=30) }\end{array}$} & \multicolumn{1}{c}{} \\
\hline HBDI & $\begin{array}{c}\text { Arithmetic } \\
\text { mean } \\
\bar{x}\end{array}$ & $\begin{array}{c}\text { Standard } \\
\text { deviation } \\
\text { s }\end{array}$ & $\begin{array}{c}\text { Arithmetic } \\
\text { mean } \\
\bar{x}\end{array}$ & $\begin{array}{c}\text { Standard } \\
\text { deviation } \\
\text { s }\end{array}$ & \multirow{2}{*}{ P } \\
\hline A-quadrant & 82.06 & 16.89 & 83.66 & 20.70 & 0.5489 \\
\hline B-quadrant & 70.45 & 13.59 & 76.03 & 15.25 & 0.1194 \\
\hline C-quadrant & 64.75 & 17.44 & 55.03 & 22.03 & $0.0200^{*}$ \\
\hline D-quadrant & 73.06 & 17.41 & 76.46 & 17.59 & 0.6103 \\
\hline
\end{tabular}

* Significant on the $5 \%$ level

Table 4 Wilcoxon scores for Professional Orientation and science students and the quadrants of the HBDI

\begin{tabular}{|c|c|c|c|c|c|}
\cline { 2 - 5 } \multicolumn{1}{c|}{} & $\begin{array}{c}\text { Professional Orientation } \\
\text { group (N=33) }\end{array}$ & \multicolumn{2}{c|}{$\begin{array}{c}\text { Science students } \\
\text { (N=38) }\end{array}$} & \multicolumn{1}{c}{} \\
\hline HBDI & $\begin{array}{c}\text { Arithmetic } \\
\text { mean } \\
\bar{x}\end{array}$ & $\begin{array}{c}\text { Standard } \\
\text { deviation } \\
\boldsymbol{s}\end{array}$ & $\begin{array}{c}\text { Arithmetic } \\
\text { mean } \\
\bar{x}\end{array}$ & $\begin{array}{c}\text { Standard } \\
\text { deviation } \\
\boldsymbol{s}\end{array}$ & $\mathrm{P}$ \\
\hline A-quadrant & 82.06 & 16.89 & 69.78 & 18.70 & $0.0066^{*}$ \\
\hline B-quadrant & 70.45 & 13.59 & 83.86 & 16.68 & $0.0003^{*}$ \\
\hline C-quadrant & 64.75 & 17.44 & 71.15 & 21.42 & 0.1964 \\
\hline D-quadrant & 73.06 & 17.41 & 63.34 & 19.99 & $0.0180^{*}$ \\
\hline
\end{tabular}

* Significant on the $5 \%$ level

As for the stated hypothesis H1 (namely, whether the mean values of the quadrant scores differ between the groups of engineering students), it follows from Table 3 that in quadrant $\mathrm{C}$, the means for the Professional Orientation students differ significantly from the means for the civil engineering students. No significant differences regarding the means for the A, B and D-quadrants occur.

Proceedings of the 2002 American Society for Engineering Education Annual Conference \& Exposition Copyright $\odot$ 2002, American Society for Engineering Education 
Regarding the stated hypothesis $\mathrm{H} 2$ (namely, whether the mean values of the quadrant scores differ between the groups of engineering and the science students) it follows from Table 4 that in the A, B and D-quadrant, the means for the engineering students on the Professional Orientation support course differ significantly from the means for the science students on their support course. No significant differences occur regarding the means for the C-quadrant.

It seems that there is a significant difference in distribution of thinking style preferences for the engineering students on the support course and science students on a support course whereas the distribution of thinking style preferences for the groups of the engineering students are similar. Information such as this should be taken into consideration when tailoring learning facilitation to the needs of the group in order to achieve whole brain learning.

Furthermore, Figure 4 illustrates the average Herrmann Brain Dominance profile of the engineering students on the support course which distinctly indicates that the preferences of the group, when combined, result in a profile that almost represents a generic whole brain profile with thinking preferences in all four quadrants. ${ }^{[5,12,13]}$ This finding endorses the necessity to structure facilitation of learning to accommodate different thinking styles and also to develop less preferred thinking modes in order to achieve the goal of whole brain learning.

Figure 4 Average Herrmann Brain Dominance profile of the 2000 students on the support course

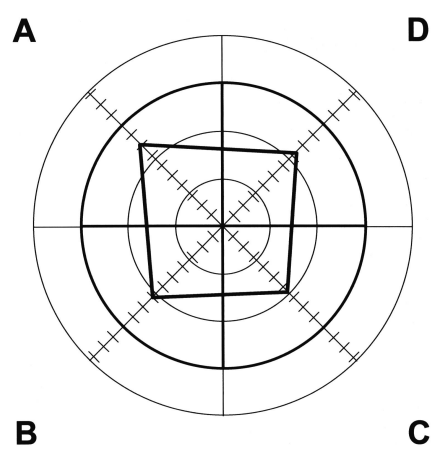

\section{Study orientation in mathematics}

The mathematics component of the support course is done independently from the main-stream calculus course and in addition to it. The aim of the mathematics activities in the support course is twofold. The first objective is to ensure that students thoroughly understand two-dimensional functions and their graphs (as the fundamental concepts that underpin a study in calculus). The second objective is that students gain insight into their own study orientation in mathematics.

To foster understanding of mathematics concepts, computer graphing technology is used to visualise and explore the graphs of two-dimensional functions in an active learning 
environment. ${ }^{[14]}$ These activities endorse individualized instruction as well as co-operative learning and involve extensive mathematics communication (orally and written).

During 2000 and 2001 the Study Orientation Questionnaire in Mathematics (SOM) ${ }^{[15]}$ was used to determine students' study orientation in mathematics. Feedback hereon was given to students individually to give them greater understanding of their own study orientation towards mathematics.

The SOM comprises six fields including 92 statements that relate to how individuals feel or act regarding aspects of their achievement in mathematics. The six fields of the SOM can be summarized as follows:

- Study attitude deals with feelings (subjective but also objective experiences) and attitudes towards mathematics that are manifested consistently and that affect students' motivation, expectation and interest with regard to mathematics.

- Mathematics anxiety concerns an "uncomfortable" feeling when faced with mathematics that can manifest in aimless behavior (like excessive sweating, scrapping of correct answers and an inability to formulate mathematics concepts).

- Study habits addresses the displaying of acquired, consistent and effective study methods.

- Problem solving behavior in mathematics includes cognitive and meta-cognitive strategies in mathematics.

- Study environment includes aspects relating to the social, physical and experience environment.

- Information processing reflects on general and specific learning, summarizing and reading strategies, critical thinking and understanding strategies like the optimal use of sketches, tables and diagrams.

In Table 5 the results of a step-wise regression analysis taking the fields of the SOM as independent variables and the performance in the first semester calculus course as dependent variable are given for the 2000 and 2001 groups respectively. 
Table 5 Step-wise regression model for the SOM and mathematics performance for 2000 and 2001

\begin{tabular}{|c|c|c|c|c|}
\hline Fields of the SOM & $\begin{array}{c}\text { Parameter } \\
\text { estimate }\end{array}$ & $\begin{array}{c}\text { Partial coefficient } \\
\text { of determination } \\
\mathbf{R}^{2}\end{array}$ & $\begin{array}{c}\text { Model/Cumulative } \\
\text { coefficient of } \\
\text { determination } \\
\mathbf{R}^{\mathbf{2}} \\
\end{array}$ & $\mathbf{P}$ \\
\hline \multicolumn{5}{|l|}{ Participants of $2000(\mathrm{~N}=30)$ : } \\
\hline Information processing (IP) & 0.2528 & 0.3918 & 0.3918 & $0.0002 *$ \\
\hline Problem-solving behaviour (PSB) & 0.1428 & 0.0772 & 0.4689 & $0.0579^{\#}$ \\
\hline \multicolumn{5}{|c|}{ Mathematics performance $=34.44+0.25 \mathrm{IP}+0.14 \mathrm{PSB}$} \\
\hline \multicolumn{5}{|c|}{ Participants of $2001(\mathrm{~N}=38)$} \\
\hline Mathematics anxiety (MA) & 0.2397 & 0.2515 & 0.2515 & $0.0013 *$ \\
\hline \multicolumn{5}{|c|}{ Mathematics performance $=45.65+0.25 \mathrm{MA}$} \\
\hline
\end{tabular}

The data in Table 5 indicates that information processing (IP), problem solving behaviour (PSB) and mathematics anxiety (MA) are significant predictors (on a 5\% or $10 \%$ level) of performance in mathematics.

\section{Writing in engineering}

A focus on effective communication (orally and written) versus language lessons only is seemingly more beneficial ${ }^{[16]}$ in developing students' technical writing skills. The challenge for faculty in the Professional Orientation support course is to develop each student's writing competence (in mathematics and in English) to a level that will ensure academic survival as an undergraduate engineering student. This inevitably implies both remedial and developmental actions. Furthermore, in order to keep the students motivated, writing activities have to be meaningful to the students and relevant not only to the content of the support course, but also to their immediate studies and to engineering in general. The following key pedagogical features, based on the four quadrant whole brain principle and active learning can be identified:

- Transparency. Students are made aware of their thinking and learning style preferences, study orientation, the four-quadrant whole brain principle and the modes of student learning (Figure 1). Specific learning activities are categorized accordingly and their relevance and meaning pointed out.

- Learner centered. Strong emphasis is placed on the active involvement of the students.

Traditional lecture style interaction is minimal. Emphasis is placed on the principle of "learning by doing". Due to the aim of the course and the deficient academic competency and existing skills of these students, this pedagogical approach inevitably results in one-to-one contact being a major form of interaction between facilitators and students. Clear instructional guidelines are also given. Nevertheless, students are not flooded with technical (language) issues nor are they spoon-fed. 
- Technology as a tool. Students enrolled for the support course do not have proficiency in the use of a word processor and application software for compiling scientific reports presumed for all engineering students at the University. Therefore training in the use of computer technology is strongly emphasized in the writing process. This approach allows students to practise technology skills, while the written assignments are generated in a format that is pleasing to them. It is also easily readable for marking and grading.

- Assignments. In order to address students' deficient writing skills both a "writing to learn" and a "learning to write" approach are followed. Writing to learn techniques ${ }^{[17]}$ focus largely on expressive writing based on a student's own experience or response to stimuli such as teaching or reading. In learning to write in engineering, assignments are chosen to include visualisation and interpretation, reflective, transactional, technical, scientific and research writing.

- Individual and co-operative learning. Worksheets in mathematics are completed individually, but informal small group discussions between two or more students invariably occur during the mathematics sessions. Although writing assignments are done individually, reports on practicals and projects are done in groups.

- Formulating and expressing of concepts. Experiences since 1993 with students taking a first course in calculus have indicated that the conceptualisation of mathematical content is a major area of incompetence. ${ }^{[3]}$ It was found that students were insecure when they had to read and comprehend mathematics and when they had to formulate mathematical concepts either orally or written. A similar incompetence with regard to scientific and technical content was found amongst the Professional Orientation students of 2000 and 2001. Speaking and writing of both English and mathematics provide effective means of overcoming this deficiency.

- Assessment An approach of continual assessment, detailed marking, grading and extensive feedback is followed because of initial remedial necessity and to aid students in developing writing competency. Although students were dismayed by their initial low grades and incompetence in both mathematical and language writing, they subsequently admitted that the experience contributed to improve their writing. This was evident in the improvement of their grades. Making students aware of their own errors is intended to enable them to assess their own writing as an engineer. Marking, grading and feedback are done by the lecturer and a language assessor but have proved to be very demanding tasks. During 2001 a "buddy system" was introduced whereby students worked in pairs and marked each other's writing assignments prior to submission for grading by the language assessor. This gave them the opportunity to scrutinize peer writing and it seemingly had a beneficial effect on improving their own writing.

\section{Student performance}

In order to ascertain the real value of the effect of the support in a developmental approach as described above, the 2000 and 2001 students will have to be followed up and an analysis of graduation tendencies made. Comparing first year academic results of the students on the Professional Orientation support course with other first year students can lead to misinterpretation because of different variables present. However, the figures (as averages in percentages) in Table 6 give some indication of the performance of students enrolled for the Professional Orientation 
support course compared to the performance of students on the standard Four Year Program and to the performance of other students on the Five Year Program who are not enrolled for the support course.

The data ${ }^{[1,2]}$ in Table 6 indicates that the mathematics performance of the students enrolled for the support course compares favorably with those of the two other groups. In fact, in the three mathematics courses their averages compare satisfactorily with those of the students on the standard Four Year Program and they consistently outperformed the other students on the Five Year Program. When interpreting these figures it should be borne in mind that the students on the support course were admitted with lower M-scores which indicated an educational background that in most cases was deficient compared to that of the other students. In the other courses their performances relative to the other groups vary, and further investigation is required to establish a pattern in the data and design appropriate interventions.

Table 6 Academic performance of first year engineering students in 2000 and 2001

\begin{tabular}{|c|c|c|c|c|c|c|}
\hline \multirow[b]{3}{*}{ Courses / semester } & \multicolumn{3}{|c|}{2000} & \multicolumn{3}{|c|}{2001} \\
\hline & \multirow[b]{2}{*}{$\begin{array}{c}\text { Four Year } \\
\text { Program } \\
\text { N=385 }\end{array}$} & \multicolumn{2}{|c|}{ Five Year Program } & \multirow[b]{2}{*}{ 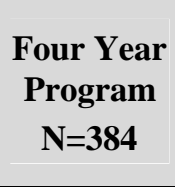 } & \multicolumn{2}{|c|}{ Five Year Program } \\
\hline & & $\begin{array}{c}\text { Support } \\
\text { course } \\
\mathbf{N}=33 \\
\end{array}$ & $\begin{array}{c}\text { Others } \\
\mathbf{N}=38\end{array}$ & & $\begin{array}{c}\text { Support } \\
\text { course } \\
\mathrm{N}=40\end{array}$ & $\begin{array}{c}\text { Others } \\
\mathrm{N}=71\end{array}$ \\
\hline \multicolumn{7}{|l|}{ First semester } \\
\hline Chemistry & 58.8 & 49.5 & 49.0 & 56.1 & 55.2 & 47.0 \\
\hline Information Technology & 63.7 & 50.7 & 59.1 & 59.5 & 47.7 & 53.1 \\
\hline Engineering drawing & 65.5 & 50.5 & 63.6 & 62.5 & 41.9 & 60.0 \\
\hline First course in Calculus & 64.1 & 61.2 & 51.6 & 61.8 & 60.3 & 49.1 \\
\hline \multicolumn{7}{|l|}{ Second semester } \\
\hline Circuits & 55.5 & 48.9 & 44.8 & 56.6 & 59.9 & 49.4 \\
\hline Materials Science & 61.1 & 53.2 & 51.8 & 54.0 & 51.4 & 47.4 \\
\hline Second course in Calculus & 64.7 & 60.6 & 53.7 & 53.1 & 58.7 & 45.0 \\
\hline Linear Algebra & 63.6 & 58.3 & 48.5 & 56.6 & 57.9 & 47.7 \\
\hline
\end{tabular}

\section{Conclusion}

Active learning and action research provide a suitable principle basis for structuring a support course as it ensures that students and faculty are involved in a dynamic process of gaining experience in learning and teaching. If this approach is applied more widely and pedagogical strategies that are beneficial to students on a support course are integrated into the curriculum of other engineering first year courses it may aid the academic development of all first year engineering students. 


\section{Acknowledgement}

The authors would like to thank the Professional Orientation students of 2000 and 2001 for their commitment and participation in the research as well as Mr. R.J. Grimbeek, statistical consultant at the University of Pretoria, for his help.

\section{References}

1. Du Plessis, G.I. Five Year Study Program Annual Report 2000, School of Engineering, University of Pretoria, Pretoria, 2001.

2. Du Plessis, G.I. Five Year Study Program Annual Report 2001, School of Engineering, University of Pretoria, Pretoria, 2002.

3. Steyn, T.M. Graphical exploration as an aid to mastering fundamental mathematical concepts - an instructional model for mathematics practicals, Masters Dissertation, University of Pretoria, Pretoria, 1998.

4. Felder, R.M. Reaching the second tier - learning and teaching styles in college science education, Journal of College Science Teaching, 23(5):286-290, 1993.

5. Herrmann, N. The creative brain ( $2^{\text {nd }}$ edition), Quebecor Printing Group, U.S.A., 1995.

6. Vander, A., Sherman, J. \& Luciano, D. Human physiology. The mechanisms of body function. McGraw-Hill Higher Education, Singapore, 2001.

7. Steyn, T.M. A learning facilitation strategy for mathematics in a support course for first year engineering students at the University of Pretoria, $\mathrm{PhD}$ thesis in preparation, University of Pretoria, Pretoria. 2002.

8. Lumsdaine, M. \& Lumsdaine, E. Creative problem solving - Thinking skills for a changing world, McGrawHill, Singapore, 1995.

9. Felder, R.M. Matters of style. ASEE Prism, December:18-23, 1996.

10. De Boer, A. \& Steyn, T. Thinking style preferences of underprepared first year students in the natural sciences, South African Journal of Ethnography, 22(3):97-102, 1999.

11. Lumsdaine, E., Lumsdaine, M. \& Schellnut, W. Creative problem solving and engineering design, Custom Publishing Group Mc Graw Hill, New York, 1999.

12. Herrmann, N. The whole brain business book, McGraw Hill, New York, 1996.

13. Herrmann, N. Twenty years of thinking about the thinking brain - A special summary of learning outcomes, Herrmann International, Lake Lure, 1998.

14. Greybe, W., Steyn, T. \& Carr, A. Fundamentals of 2-D function graphing - A practical workbook for precalculus and introductory calculus, Oxford University Press, Cape Town, 1998.

15. Maree, J.G. The development and evaluation of a study orientation questionnaire in mathematics, $\mathrm{PhD}$ thesis, University of Pretoria, Pretoria. 1997.

16. Mahan, J.E., Jayasumana, A., Lile, D. \& Palmquist, M. Bringing an emphasis on technical writing to freshman course in electrical engineering, IEE Transaction on Education, Vol.43, No.1, February 2000.

17. Emerson, L. A collaborative approach to the teaching of writing in the sciences in a New Zealand tertiary context, $\mathrm{PhD}$ thesis, University of Massey, Palmerston North.

Proceedings of the 2002 American Society for Engineering Education Annual Conference \& Exposition Copyright $\odot$ 2002, American Society for Engineering Education 


\section{TOBIA STEYN}

Tobia Steyn holds degrees in mathematics and education and has been involved in academic support programs at the University of Pretoria since the early 1990's, initially focusing on mathematics support in the Faculty of Science and from 1999 as senior lecturer responsible for the support course in the School of Engineering. She is certified in the administration and interpretation of the Herrmann Brain Dominance Instrument.

\section{JASPER STEYN}

Jasper Steyn is professor of mechanical engineering at the University of Pretoria. He was head of department from 1990 until 2000 and was also Chairman of the School of Engineering in 2000. In 2001 he was a Visiting Fellow at the Sloan School of Management at the Mas sachusetts Institute of Technology. He is a past president of the South African Institution of Mechanical Engineering and is a registered professional engineer. 